\title{
Effect of Screw Speed, Drawing Ratio and PET Concentration on the Properties of PET/PP Blends
}

\author{
I. Gokgoz Erkoc ${ }^{a, *}$, T. Guven ${ }^{b}$, F. Yildirim ${ }^{b}$, M. Sözer ${ }^{c}$ And F. GÜneR ${ }^{c}$ \\ ${ }^{a}$ Istanbul Technical University, Department of Polymer Science and Technology, 34467, Istanbul, Turkey \\ ${ }^{b}$ Mir R\&D Co.Ltd. Yildiz Technical University Teknopark, 34220, Istanbul, Turkey \\ ${ }^{c}$ Istanbul Technical University, Department of Chemical Engineering, 34467, Istanbul, Turkey
}

\begin{abstract}
The objective of this study is to investigate the influence of screw speed, drawing ratio and composition of blend on the morphology and the mechanical properties of extruded and drawn PET/PP blends. Samples were generated by a two-step process. Firstly, PET was dispersed in PP matrix at different extrusion screw speeds in order to determine optimum mixing condition, and then extrudates were stretched by a take up device. Final morphology and mechanical properties of the samples were examined using scanning electron microscopy, dynamic mechanical analysis, and a universal testing machine. The results showed that low screw speeds were not enough to distribute PET droplets homogeneously inside the matrix. With increasing of the screw speed more homogeneous phase morphology was obtained but further increase caused to agglomeration of PET droplets. Scanning electron microscopy images also showed that with increasing of draw ratio PET droplets changed from spherical to rod-like shape, and finally to microfibrils in matrix. It was also found that with increasing of concentration of PET and draw ratio, mechanical properties increased up to 6-7 times compared to non-oriented samples.
\end{abstract}

DOI: 10.12693/APhysPolA.134.442

PACS/topics: polymer blend, drawing, fibrillation, polypropylene, polyethylene terephthalate

\section{Introduction}

Polypropylene (PP) is one of the most commodity polymers used in a number of industries including packaging, household goods, automotive, infrastructure, and textile. It is relatively inexpensive and it can be processed by all methods such as extrusion, injection molding, blow molding, and cast film. In spite of the impressive properties, there are some restrictions in mechanical performance of PP when using in specific products such as automotive interior parts and plastic pipes [1]. Compounding with functional fillers like glass fiber can greatly enhance the mechanical properties of PP. However, this kind of filler is abrasive, not eco-friendly and expensive. In today's market conditions, producers have been constantly looking for a ways to provide more economic and eco-friendly solutions for their products.

Blending of two or more polymers is another technique to improve desired properties of matrix polymer. This method has become more economic way for developing new materials than their synthesis [2]. However, most of polymers are thermodynamically incompatible due to differences in their chemical structure. Therefore, after mixing them numerous types of phase morphologies is obtained such as fibrillar, droplet, co-continuous, or laminar. For example, laminar structure of the dispersed phase which is often generated via film extrusion or blow molding process improves the barrier properties, whereas fibril-like structure enhances the mechanical properties of

*corresponding author; e-mail: gokgozi@itu.edu.tr the blend [3-7]. Studies have shown that interfacial adhesion, properties of components, blend composition and processing conditions play predominant roles in blend morphology [8-14].

Over the past few years researchers have developed a new type of material known as microfibrillar reinforced composites (MFC) and blends (MFB) in order to achieve fibril blend morphology. Due to enhanced mechanical properties, this method offers a competitive advantage when compared to traditional blending technique.

Basically three steps are used to prepare MFC material:

1. Components are mixed via extruder.

2. Drawing is applied to align all components in one direction. In this step prepared oriented blends are named as MFBs.

3. The second step is followed by a thermal treatment (or isotropization) process which occurs at between the melting temperatures of the blend components. The main aim of this step is randomly distributing reinforced polymer in the matrix phase. This can be achieved with compression molding or injection molding equipment $[8,15-17]$. The material obtained at the end of this process is called MFC.

In contrast to conventional polymer blending techniques, MFC and MFB materials are produced by immiscible polymers. In several studies low-density polyethylene (LDPE), high-density polyethylene (HDPE) and PP were used for matrix polymer and reinforced by other polymers such as liquid crystal polymers (LCP). Despite LCP's outstanding features such as rigid-rod molecular 
structure, which provides better orientation, its high cost limits its use in commodity products $[18,19]$. In this study, polyethylene terephthalate (PET) was preferred as a reinforcement material for PP due to its relatively low cost, fiber forming capability, relative good mechanical properties, and recyclability.

This work focused on the effects of screw speed, drawing ratio and blend composition on the morphology and static-dynamic mechanical properties of extruded and drawn PET/PP blends.

\section{Materials and methods}

During the study, polypropylene random copolymer (PPRC), a special type of PP which is developed especially for plastic pipe production (Sabic-Vestolen 9421, MFI: $0.5 \mathrm{~g} / 10 \mathrm{~min}$ at $190^{\circ} \mathrm{C}, 5 \mathrm{~kg}$ and density $898 \mathrm{~kg} / \mathrm{m}^{3}$ ) and bottle grade PET granule (intrinsic viscosity 0.72 $0.82 \mathrm{dl} / \mathrm{g}$ ) were used.

First of all PET was dried in a vacuum oven at $100^{\circ} \mathrm{C}$ for at least $12 \mathrm{~h}$ in order to avoid hydrolysis, then mixed with $\mathrm{PP}$ in a co-rotating twin screw extruder (Xinda PSHJ-35 screw diameter: $36 \mathrm{~mm}, \mathrm{~L} / \mathrm{D}$ ratio: 44, rectangular die: $12 \times 1.5 \mathrm{~mm}^{2}$ ) which is a medium sized industrial production line. PP was fed to extruder from the side feeding zone to prevent thermal degradation under high temperature. The temperature profile starting from the hopper to the die was set at $225^{\circ} \mathrm{C}, 245^{\circ} \mathrm{C}, 255^{\circ} \mathrm{C}$, $265^{\circ} \mathrm{C}$, and $250^{\circ} \mathrm{C}$. Then the hot extrudates were immediately quenched in a water bath at about $20^{\circ} \mathrm{C}$.

At the beginning of study, the melt blending of $\mathrm{PET} / \mathrm{PP}$ was carried out using screw rates $150,240,300$, and $360 \mathrm{rpm}$ while the weight ratio of PET was maintained at $30 \mathrm{wt} \%$.

At the second step, to obtain fibrillary morphology the extrudates were subjected to orientation by a take up device which consists of a three godets (rolls) system. In order to gain enough chain flexibility, temperature of godets was maintained at $100^{\circ} \mathrm{C}$ and various draw ratios were applied by adjusting their speed. The speed of first and second godet were maintained at the constant level while the speed of third godet was gradually increased. The speed ratio of first and second godet was used to calculate draw ratio (DR). The procedures for preparing the samples are illustrated in Fig. 1.

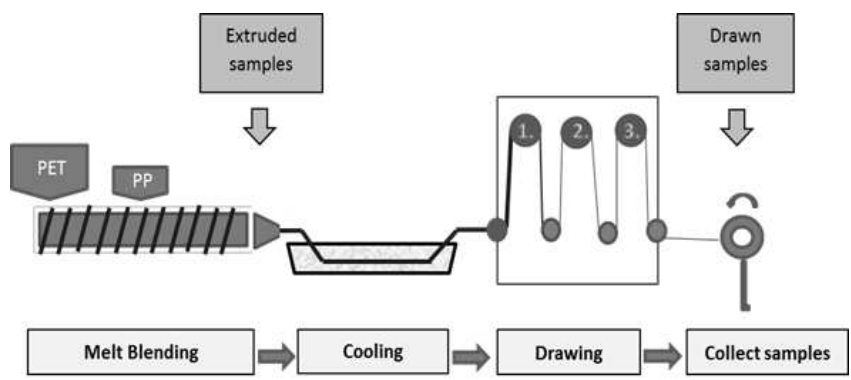

Fig. 1. Schematic diagram of preparing oriented/nonoriented $\mathrm{PET} / \mathrm{PP}$ blend samples via twin screw extruder.

\section{Characterization}

Tensile properties of drawn blends (MFBs) in tape shape were performed by universal testing machine (Instron 5567 equipped with $10 \mathrm{kN}$ load cell) at room temperature with cross head speed of $50 \mathrm{~mm} / \mathrm{min}$. The average value of the cross-section was calculated from at least six point measurements.

Dynamic mechanical analysis (DMA) was carried out by DMA Q800 system from TA Instruments. The storage modulus and mechanical damping factor values (tan delta) of PET/PP blends were conducted in the film tension mode from $30^{\circ} \mathrm{C}$ to $150^{\circ} \mathrm{C}$ at a fixed frequency of $1 \mathrm{~Hz}$ and a heating rate of $3^{\circ} \mathrm{C} / \mathrm{min}$.

The surface morphology of the fractured specimens was studied using a scanning electron microscope (SEM), Quanta FEG 250. The acceleration voltage was $10 \mathrm{kV}$. Extruded and drawn PET/PP blends were immersed in liquid nitrogen and fractured. All specimens were coated with a thin $\mathrm{Au} / \mathrm{Pd}$ layer (about $4 \mathrm{~nm}$ in one minute $20 \mathrm{~mA}$ ) by Edwards RV3 coater. The average diameter of the droplets and fibrils were measured by using image processing software (ImageJ, U.S. National Institutes of Health, Bethesda, Maryland, USA).

\section{Results and discussion}

\subsection{Effect of screw speed on morphology}

Control of blend morphology is extremely important to gain desired final properties. To investigate the influence of screw speed on the phase morphology in PET/PP blends, samples with $30 \mathrm{wt} \%$ PET were prepared at different speed rates. Figure 2 shows SEM micrographs of these blends. As seen in pictures, relatively low screw speeds (150 rpm and $240 \mathrm{rpm}$ ) are not enough to distribute and melt to PET droplets well in continuous phase of PP. When the rotation speed was increased to $300 \mathrm{rpm}$, typical incompatible blend morphology was obtained. At this screw speed PET droplets were dispersed at the spherical and elliptical forms in the PP matrix phase (Fig. 2e,f). However, when the speed reached $360 \mathrm{rpm}$ the morphology changed and PET droplets began to agglomerate (Fig. 2g,h). Normally, due to the droplet breakup behavior, finer droplet morphology is expected at high screw speeds. However, previous studies have shown that acceleration of droplet coalescence with increasing screw speed can be a reason for agglomeration of dispersed phase [12, 20-24].

PET and PP phase were subject to pull out during the cryogenic fracture, and this caused to holes in the blend morphology. According to the SEM results, screw speed was set at $300 \mathrm{rpm}$ for next studies.

\subsection{Effect of drawing on morphology}

Figure 3 presents the fracture surface morphologies of extruded and drawn $\mathrm{PET} / \mathrm{PP}$ blends which were prepared in a weight ratio of $30 / 70$. It can be seen that with increasing the drawing ratio, the PET droplets resulted 

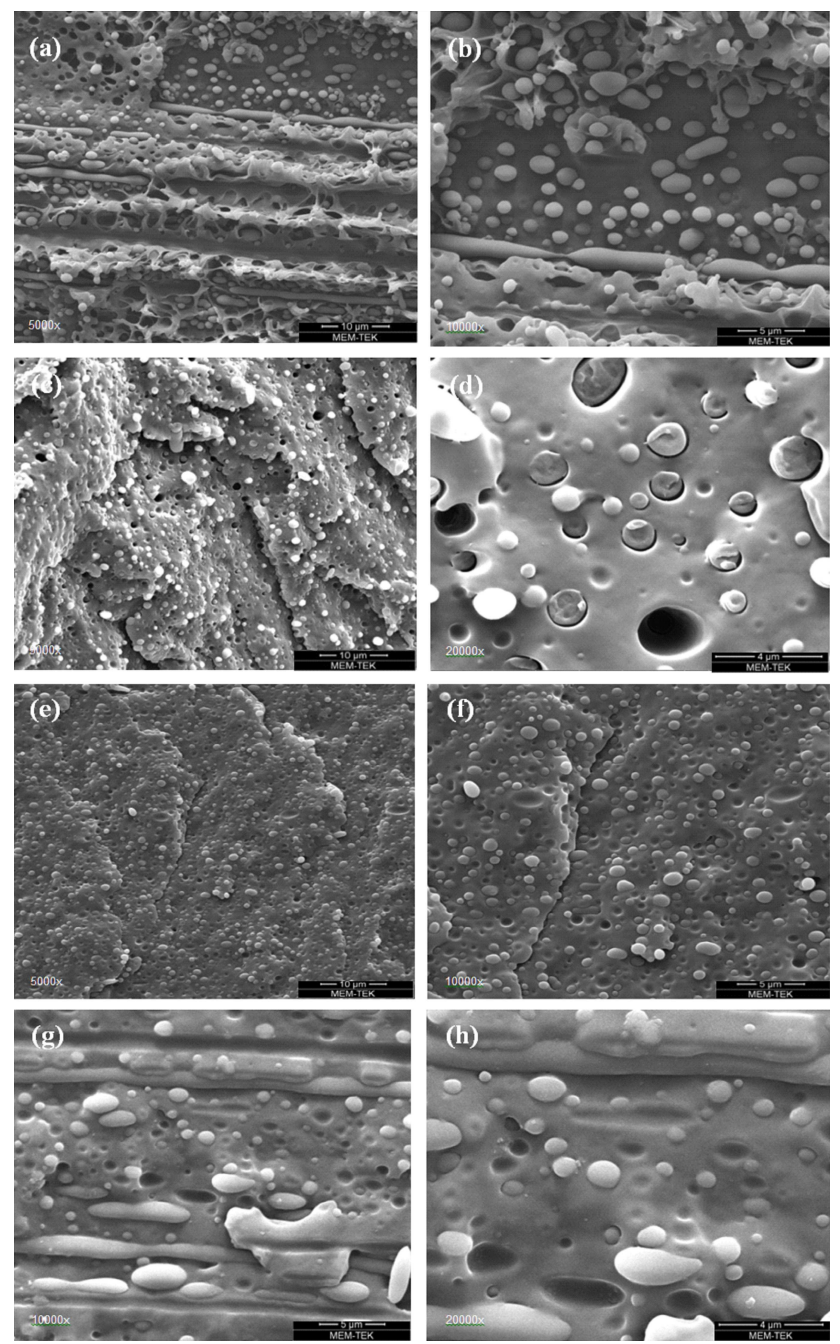

Fig. 2. Morphology of the fracture surfaces of the extruded $\mathrm{PET} / \mathrm{PP}$ blend samples prepared at screw speeds: (a)/(b) $150 \mathrm{rpm}, \quad(\mathrm{c}) /(\mathrm{d}) 240 \mathrm{rpm}, \quad(\mathrm{e}) /(\mathrm{f})$ $300 \mathrm{rpm},(\mathrm{g}) /(\mathrm{h}) 360 \mathrm{rpm}$.

in a highly oriented fibrillar structure. Additionally, with drawing, all components of the blend were aligned parallel to the flow direction. Technically it is hard to measure length of fibrils and therefore change of dispersed phase diameter was determined by image processing software (Fig. 4). Compared to the extruded blend, there is a considerable change in size and distribution of dispersed phase after drawing.

\subsection{Effect of drawing and concentration on static/dynamic mechanical properties}

The effect of PET concentration and drawing ratio on mechanical properties are graphically represented in Fig. 5a,b. Test results showed that tensile modulus and strength values are greatly improved by drawing process. Depending on the PET concentration and draw ratio, mechanical properties increased up to 6-7 times in comparison to non-oriented blends. However, it can
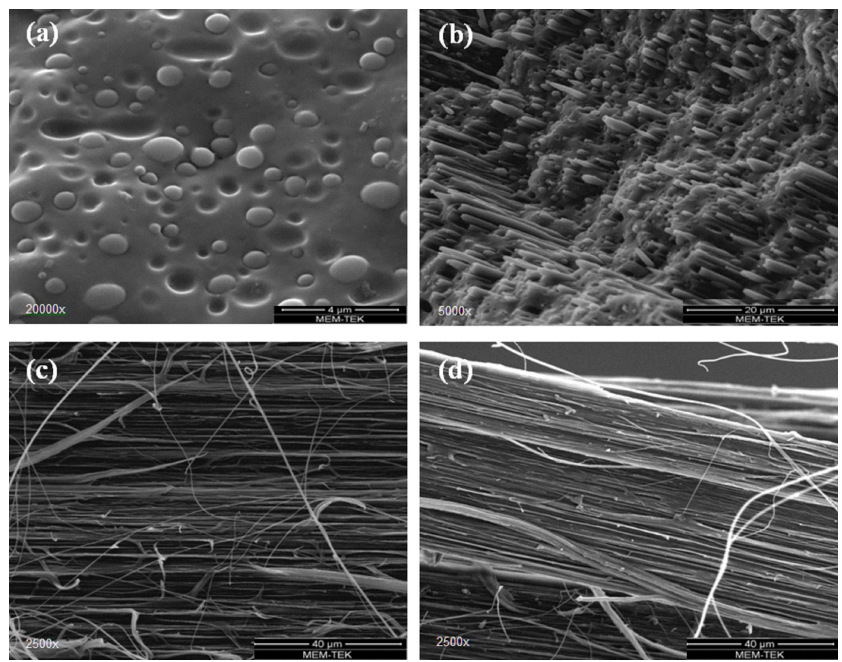

Fig. 3. Morphology of the fracture surfaces of the extruded and drawn blend samples prepared at (a) die exit (transverse direction), (b) DR:1, (c) DR:3, (d) DR:5 (longitudinal direction).

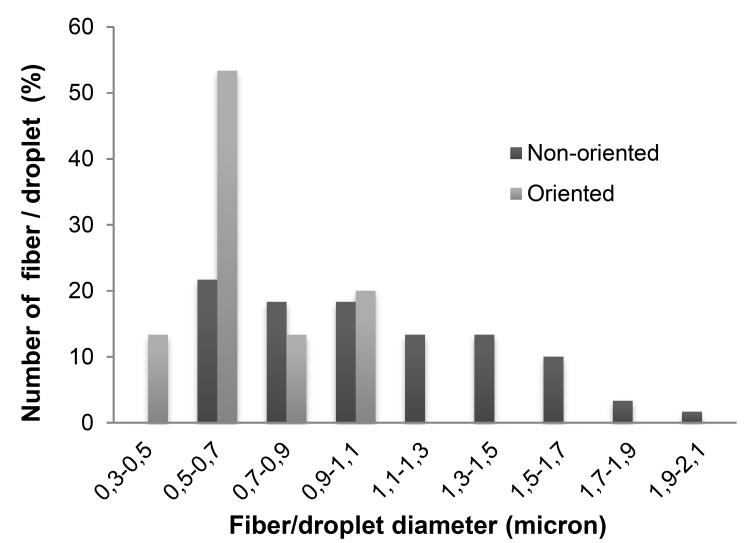

Fig. 4. Effect of orientation on the distribution of PET droplet and fiber diameters.

be noticed that tensile modulus showed a tendency to decrease at $40 \mathrm{wt} \% \mathrm{PET}$. PP and PET are known incompatible polymer pairs and the lack of interfacial adhesion between these two polymers and agglomeration of PET droplets could be the cause of decrease in mechanical performance at high PET concentrations [25].

With DMA, it is possible to determine viscoelastic properties of polymers by applying a small sinusoidal deformation under a controlled stress or strain. The sample elastic behavior is measured by the storage modulus, while its energy dissipation is measured by tan delta which is often named the damping factor.

In the present study, the storage modulus, and tan delta of $\mathrm{PET} / \mathrm{PP}$ blends were investigated in a wide range of temperature and various $\mathrm{PET}$ concentrations (Figs. 6, 7). As seen in Fig. 6, the storage modulus values show a sharp decline with temperature before they 

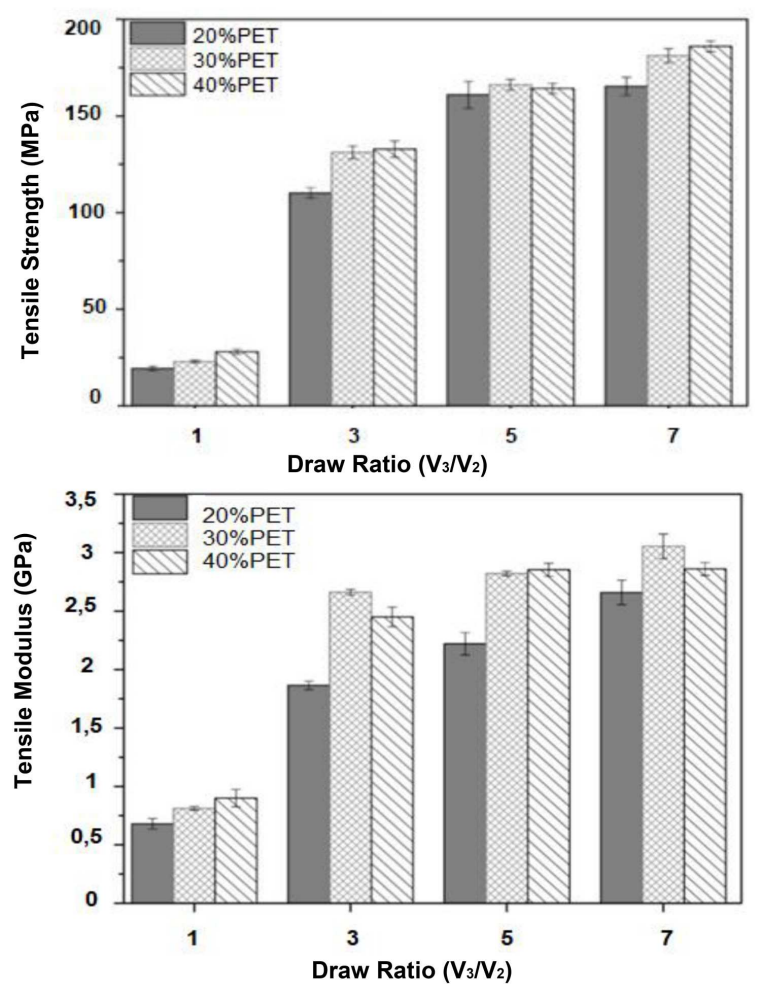

Fig. 5. Variation of (a) tensile strength and (b) tensile modulus with draw ratio at different PET compositions.

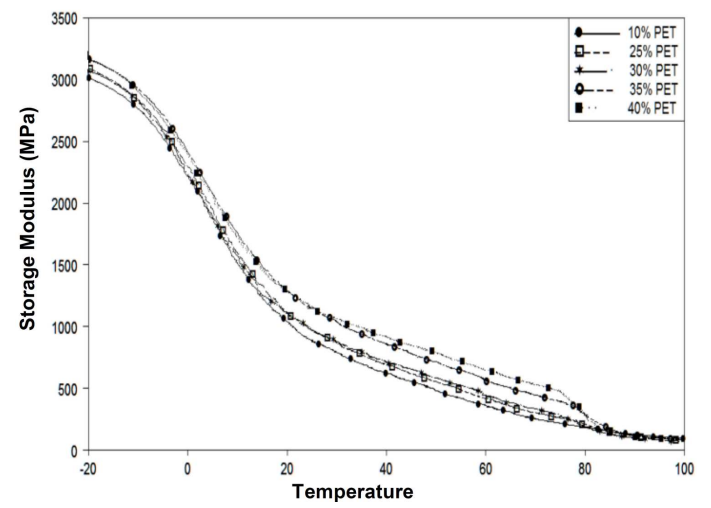

Fig. 6. Variation of storage modulus with temperature at different PET compositions.

approach the constant value. This behavior is closely related to molecular motion of polymer chains. At low temperature, modulus is high due to the lack of free volume for molecular mobility. However, with increased the temperature, free volume between the polymer chains increases which causes molecular mobility. As a result of this, modulus of sample decreases with temperature until viscous region start. It was also observed that addition of PET improves the storage modulus values of blends.

Tan delta plots of extruded PET/PP blends are illustrated in Fig. 7. As seen in the figure, the intensity of the peaks strongly depend on the PET concentration. Addi-

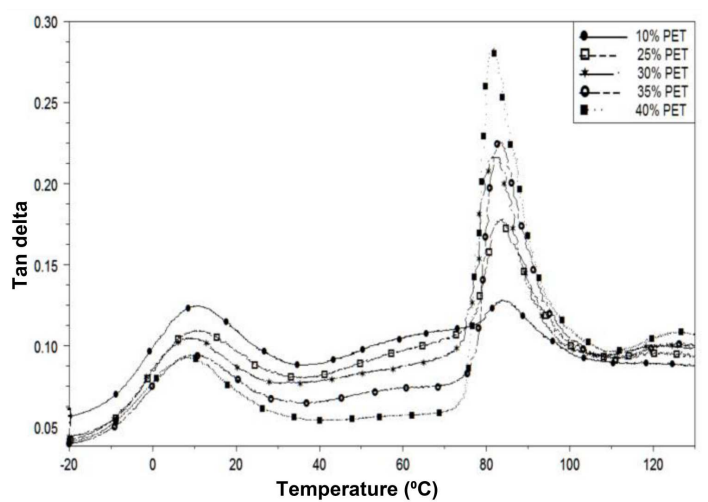

Fig. 7. Variation of tan delta with temperature at different PET compositions.

tion of PET to the PP matrix causes a decrease in the intensity of PP peaks. This indicates that after blending, the mobility of polymer chains is restricted.

The glass transition temperature $T_{g}$ is an important thermophysical property of polymers. Mechanical properties such as strength, elongation, toughness are directly related to this temperature. Additionally, determination of the $T_{g}$ is the most widely used method for understanding miscibility of polymers. Glass transition temperature can be measured from maximum damping temperature. Miscible blends show a single glass transition temperature which is located between the $T_{g}$ values of components. However, in immiscible blends more than one transition temperature are obtained (Fig. 7).

\section{Conclusion}

Blending of polymers is one of the important commercial methods to develop new materials in the plastic industry. The final properties of blends are closely dependent on phase morphology of the blend. This is the reason why companies and researchers have been studying on controlling blend morphology. As known, in most commercial blends, reinforced polymer is generally distributed in a droplet structure. However investigations indicated that with applying processes such as orientation, the morphology of reinforced phase can be changed from droplet to fibrillar or lamellar structure. This provides significant improvements in final properties $[5,8-$ 14]. In this study, some kind of $\mathrm{PET} / \mathrm{PP}$ blends were prepared with a semi-commercial twin screw extruder to investigate the effect of screw speed, drawing ratio and blend composition on mechanical and morphological properties. Under the experimental conditions, it can be concluded that low and high screw speeds were not suitable for good blend morphology. In this study, $300 \mathrm{rpm}$ was selected to achieve desired blend morphology. In addition, depending on the PET concentration and applied draw ratio, fibril diameters decreased to $300 \mathrm{~nm}$ and mechanical properties increased up to 6-7 times in comparison to non-oriented samples. The effect of tempera- 
ture and concentration on dynamic mechanical properties like storage modulus, and mechanical damping of nonoriented $\mathrm{PET} / \mathrm{PP}$ blends were also investigated. The results showed that strorage modulus values were decreased with temperature, and increased with PET concentration. Intensity of tan delta peaks of PP reduced with increasing PET content in the blend.

\section{Acknowledgments}

Some parts of this study was realized at Akron University Laboratories, so the authors gratefully acknowledge the Scientific and Technical Research Council of Turkey (TUBITAK) to provide international research scholarship with 2214-A program (1059B141400691) and Professor Mukerrem Cakmak for valuable supports. The authors would like to thank also MIR R\&D Co.Ltd. for production and material support and ITU MEMTEK for SEM measurements.

\section{References}

[1] I.M. Inuwa, A. Hassan, S.A. Samsudin, M.K.M. Haafiz, M. Jawaid, J. Vinyl Addit. Tech. 23, 45 (2017).

[2] E.R. Sadiku, E.S. Ogunniran, Nanostructured Polymer Blends, William Andrew, Elsevier, UK 2014.

[3] A.M. Grumezescu, Food Packaging-Nanotechnology in the Agri-Food Industry, Academic Press, Elsevier, UK 2017.

[4] V. Siracusa, Int. J. Polym. Sci. 2012, 11 (2012).

[5] C. Harrats, S. Thomas, G. Groeninckx, Micro and Nanostructured Multiphase Polymer Blend Systems: Phase Morphology, and Interphases, Taylor \& Francis Group, FL 2006.

[6] R.J. Shields, D. Bhattacharyya, S. Fakirov, J. Mater Sci. 43, 6758 (2008).

[7] M.A. Huneault, Z.H. Shi, L.A. Utracki, Polym. Eng. Sci. 35, 115 (1995).
[8] K. Friedrich, M. Evstatiev, S. Fakirov, O. Evstatiev, M. Ishii, M. Harrass, Composit. Sci. Technol. 65, 107 (2005).

[9] A.I. Isayev, S. Palsule, Encyclopedia of Polymer Blends, Vol. 2: Processing, Wiley, Germany 2011.

[10] P.V. Van Puyvelde, P. Moldenaers, Rheol. Rev. 101, 145 (2005).

[11] S. Thomas, R. Shanks, S. Chandrasekharakurup, Design and Applications of Nanostructured Polymer Blends and Nanocomposite, Elsevier, UK 2016.

[12] J.K. Lee, C.D. Han, Polymer 41, 1799 (2000).

[13] R. Su, K. Wang, Q. Zhang, F. Chen, Q. Fu, Chin. J. Polym. Sci. 28, 249 (2010).

[14] R. Gonzalez-Nunez, B.D. Favis, P.J. Cafweau, Polym. Eng. Sci. 33, 851 (1993).

[15] J. Karingamanna, T. Sabu, J. Kuruvilla, J. Polym. Res. 18, 1 (2011).

[16] J. Karingamanna, T. Sabu, J. Kuruvilla, Composit. Part A Appl. Sci. Manufact. 39, 164 (2008).

[17] K. Friedrich, M. Evstatiev, S. Fakirov, O. Evstatiev, Int. J. Polym. Mater. 53, 211 (2004).

[18] S. Sombatdee, S. Saikrasun, T. Amornsakchai, J. Reinforc. Plast. Composit. 28, 2983 (2009).

[19] Z.Z. Denchev, Recent Res. Devel. Appl. Pol. Sci. 3, 119 (2006).

[20] W. Li, Ph.D. Thesis, Technische Universität Kaiserslautern, 2009.

[21] Y.G. Cho, M.R. Kamal, Polym. Eng. Sci. 42, 2005 (2002).

[22] A. Luciani, J. Jarrin, Polym. Eng. Sci. 36, 1619 (1996).

[23] J.M. Willis, B.D. Favis, J. Lunt, Polym. Eng. Sci. 30, 1073 (1990).

[24] J.K. Lee, C.D. Han, Polymer 41, 1799 (2000).

[25] P. Taepaiboon, J. Junkasem, R. Dangtungee, T. Amornsakchai, P. Supaphol, J. Appl. Polym. Sci. 102, 1173 (2006). 